\title{
Scrotal Migration of the Peritoneal Catheter of a Ventriculoperitoneal Shunt in a 5-Year-Old Male -Case Report-
}

\author{
Daisuke KITA, Yasuhiko HAYASHI, Masashi KINOSHITA, \\ Kazunori OHAMA*, and Jun-ichiro HAMADA \\ Department of Neurosurgery, Kanazawa University Hospital, \\ Kanazawa University, Kanazawa, Ishikawa; \\ ${ }^{*}$ Department of Pediatric Surgery, Ishikawa Prefectural Central Hospital, Kanazawa, Ishikawa
}

\begin{abstract}
A 5-year-old male presented with scrotal migration of the catheter from a ventriculoperitoneal shunt manifesting as left scrotal swelling 4 months after implantation. Surgical obliteration of the patent peritoneal processus vaginalis that forms a corridor from the peritoneum to the scrotum was performed to avoid shunt malfunction. Review of the 26 reported cases including the present case revealed that most patients were up to 18 months old. Our patient was the oldest. Migration tended to occur within 6 months after implantation (mean 3.8 months, median 1.0 month). Involvement of the right side of the scrotum was prevalent (23 of 26 cases). Patent processus vaginalis and small peritoneal cavity probably contribute to scrotal catheter migration.
\end{abstract}

Key words: ventriculoperitoneal shunt complication, peritoneal catheter migration, patent processus vaginalis, scrotal migration

\section{Introduction}

Ventriculoperitoneal (VP) shunting is the most commonly used technique for the management of hydrocephalus,

Received March 25, 2010; Accepted May 11, 2010 although complications occur occasionally. ${ }^{21)}$ Catheter migration into or perforation of the intestine, vagina, umbilicus, or scrotum is a rare but potential complication, especially in children. ${ }^{4)}$ We treated a 5 -year-old boy with peritoneal catheter migration into the left scrotum and discuss the characteristics of scrotal catheter migration. 


\section{Case Report}

A 5-year-old boy without a history of relevant past illness suffered headache and vomiting persisting for a week. Computed tomography (CT) and magnetic resonance imaging revealed obstructive hydrocephalus due to craniopharyngioma. A VP shunt system (Codman-Hakim programmable valve system, Cat. \#82-3113; Johnson \& Johnson Co., New Brunswick, N.J., U.S.A.) was implanted

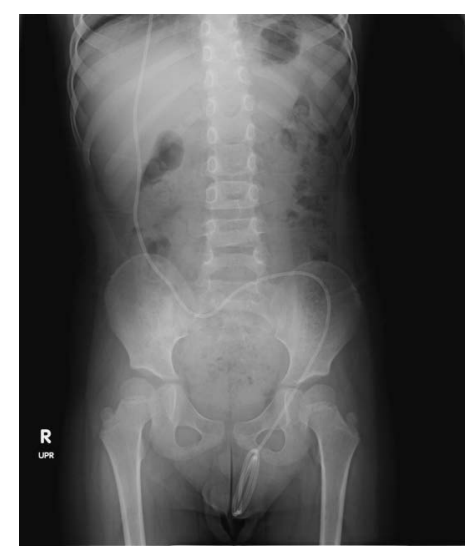

Fig. 1 Abdominal radiograph showing migration of a coiled peritoneal catheter of the ventriculoperitoneal shunt into the left scrotum. and 2 weeks later the tumor was surgically removed. The postoperative course was uneventful except for diabetes insipidus which was treatable with nasal desmopressin spray. Swelling of the left scrotum was noted 4 months after implantation of the VP shunt. Abdominal radiography provided clear evidence that the coiled peritoneal catheter had migrated into the left scrotum (Fig. 1). Head CT excluded ventriculomegaly associated with shunt malfunction. The catheter migration was easily repaired by manual compression of the swollen scrotum. Prophylactic obliteration of the patent processus vaginalis was then performed by pediatric surgeons to prevent further shunt complications such as incarceration of the catheter or shunt malfunction.

\section{Discussion}

Migration of the peritoneal catheter into the scrotum has been reported in 26 patients (Table 1). ${ }^{1-5,7-14,17-20)}$ Scrotal migration occurred during infancy or early life (between 4 days to 5 years of life, mean 17.1 months). Fifteen of the 26 patients were younger than 12 months old and 21 cases were up to 18 months old at the time of the migration (Fig. $2 \mathrm{~A}$ ). The present case, at 5 years of age, is the oldest patient documented to date, and no adult case has been reported. The interval between the latest shunt implantation and the scrotal migration ranged from 1 day to 30 months (mean 3.8 months, median 1.0 month). Twentyone of 25 migrations occurred within 6 months of implan-

Table 1 Summary of previous and the present cases

\begin{tabular}{|c|c|c|c|c|}
\hline Case No. & Author (Year) & Age at migration & Interval $^{*}$ & Affected side \\
\hline 1 & Ramani (1974) ${ }^{14)}$ & $5 \mathrm{mos}$ & $5 \mathrm{mos}$ & $\mathrm{rt}$ \\
\hline 2 & Cooper et al. $(1976)^{2)}$ & $1 \mathrm{mo}$ & 10 days & $\mathrm{rt}$ \\
\hline 3 & Bristow et al. $(1978)^{1)}$ & $10 \mathrm{mos}$ & 1 day & $\mathrm{rt}$ \\
\hline 4 & Villarejo and Blazquez $(1980)^{17)}$ & 7 mos & $1 \mathrm{mo}$ & $\mathrm{rt}$ \\
\hline 5 & Crofford and Balsam (1983) ${ }^{3)}$ & 3 mos & 2 mos & $\mathrm{rt}$ \\
\hline 6 & & $4 \mathrm{mos}$ & $1 \mathrm{mo}$ & $\mathrm{rt}$ \\
\hline 7 & & $6 \mathrm{mos}$ & 6 mos & $\mathrm{rt}$ \\
\hline 8 & & 4 yrs & $2 \mathrm{mos}$ & lt \\
\hline 9 & Fuwa et al. (1984) ${ }^{5)}$ & 13 mos & 12 mos & $\mathrm{rt}$ \\
\hline 10 & Kobayashi et al. (1987) & 23 days & 3 days & $\mathrm{rt}$ \\
\hline 11 & & 3 yrs 9 mos & $9 \mathrm{mos}$ & $\mathrm{rt}$ \\
\hline 12 & Ram et al. (1987) ${ }^{13)}$ & 3 yrs & $2.5 \mathrm{yrs}$ & $\mathrm{rt}$ \\
\hline 13 & Kwok et al. (1989) ${ }^{9)}$ & $6 \mathrm{mos}$ & $1 \mathrm{wk}$ & rt \\
\hline 14 & Wong $(1994)^{20)}$ & $8 \mathrm{mos}$ & 4 wks & $\mathrm{rt}$ \\
\hline 15 & Oktem et al. $(1998)^{10)}$ & $2.5 \operatorname{mos}$ & 1 day & lt \\
\hline 16 & & $4 \mathrm{mos}$ & $4 \mathrm{mos}$ & rt \\
\hline 17 & & $7.5 \mathrm{mos}$ & $5 \mathrm{mos}$ & $\mathrm{rt}$ \\
\hline 18 & & $16 \mathrm{mos}$ & $6 \mathrm{mos}$ & $\mathrm{rt}$ \\
\hline 19 & Ozveren et al. (1999) ${ }^{11)}$ & 4 days & 1 day & $\mathrm{rt}$ \\
\hline 20 & Ward et al. (2001) ${ }^{19)}$ & $18 \mathrm{mos}$ & $4 \mathrm{hrs}$ & $\mathrm{rt}$ \\
\hline 21 & Walsh and Kombogiorgas (2004) ${ }^{18)}$ & 17 mos & $6 \mathrm{mos}$ & $\mathrm{rt}$ \\
\hline 22 & de Aquino et al. $(2006)^{4)}$ & 42 days & 31 days & $\mathrm{rt}$ \\
\hline 23 & & 14 mos & 14 mos & $\mathrm{rt}$ \\
\hline 24 & Karaosmanoglu et al. (2008) ${ }^{7)}$ & $14 \mathrm{mos}$ & n.a. & $\mathrm{rt}$ \\
\hline 25 & Rahman and Lakhoo $(2009)^{12)}$ & 4 yrs & $1 \mathrm{mo}$ & $\mathrm{rt}$ \\
\hline 26 & Present case & 5 yrs 4 mos & $4 \mathrm{mos}$ & lt \\
\hline
\end{tabular}

*The interval between the latest ventriculoperitoneal shunt implantation and scrotal migration. n.a.: not available. 

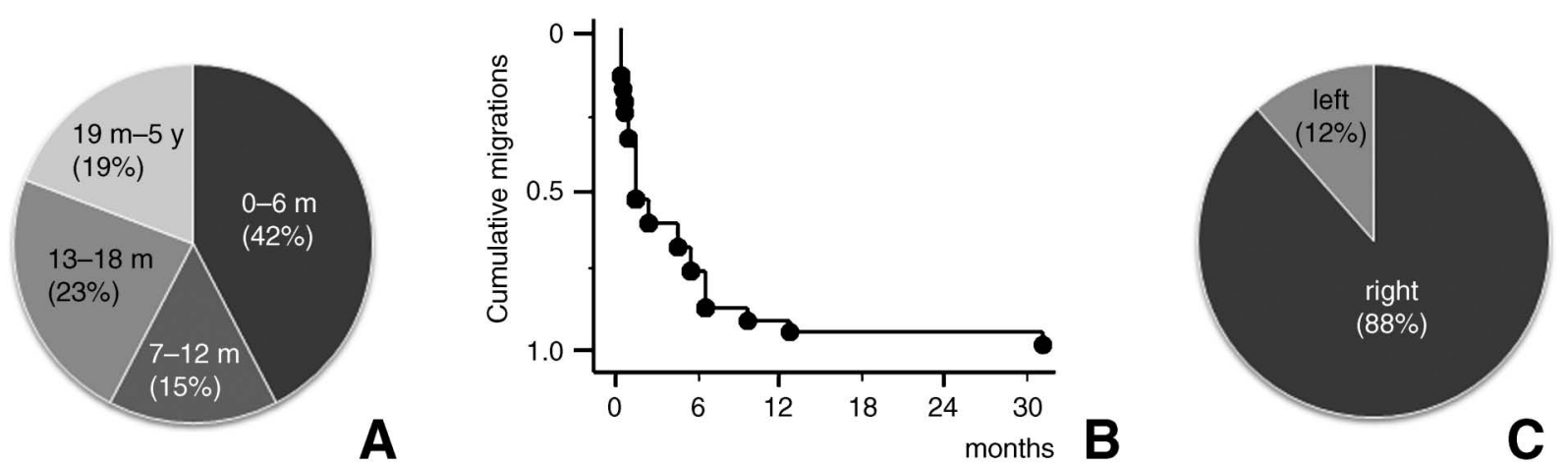

Fig. 2 A: Circle graph showing the age distribution at scrotal migration. Of 26 patients, 21 were younger than or equal to 18 months. m: months, y: years. B: Survival graph showing the interval between the latest shunt implantation and scrotal migration. The interval ranged from 1 day to 30 months (mean 3.8 months, median 1.0 month); 21 of 25 reported migrations occurred within 6 months. C: Circle graph showing predominance of the right side for scrotal migration (23 of 26 cases).

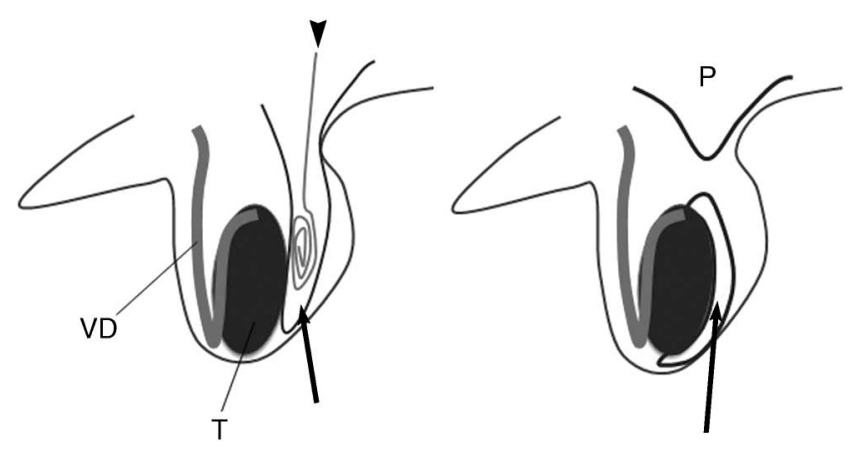

Fig. 3 Left: Schematic drawing of patent processus vaginalis (arrow) and the catheter (arrowhead) migrated into the scrotum. T: testis, VD: vas deferens. Right: Processus vaginalis becomes the scrotal tunica vaginalis (arrow) after separation from the peritoneum $(P)$.

tation (one not reported) (Fig. 2B). Involvement of the right side of the scrotum predominated (23 of 26 cases) (Fig. 2C), which is roughly consistent with the distribution of inguinal hernias in children (right $60 \%$, left $30 \%$, bilateral $10 \%$ ) according to surveys of 2,764 cases in the U.S.A. ${ }^{15)}$ and 5,686 cases in Japan. ${ }^{22)}$

The catheter entered into the scrotum from the patent processus vaginalis, which becomes the scrotal tunica vaginalis after separation from the peritoneum (Fig. 3). The processus vaginalis remains patent in $90 \%$ of boys at birth, $50-60 \%$ at age 1 year, ${ }^{6)} 40 \%$ between 2 and 16 years of age, and $15-30 \%$ in adulthood. ${ }^{15)}$ Increase in abdominal pressure following VP shunt implantation and in the inflow of cerebrospinal fluid may be a causative factor in the prolonged patency of the processus vaginalis. ${ }^{6,7,11)}$ In addition, the residual peritoneal volume is linearly correlated with the body surface area, at approximately $80 \mathrm{ml} / \mathrm{m}^{2}{ }^{2}{ }^{16}$ ) Younger children tend to have patent processus vaginalis and smaller peritoneal cavity, so the VP shunt catheter may easily migrate into the scrotum. Prompt surgical obliteration of the processus vaginalis and catheter repositioning are strongly recommended to avoid the risk of incarceration of the catheter and further VP shunt malfunction, but the shunt rarely requires revision. ${ }^{3,4)}$

The present 5-year-old boy with VP shunt catheter migration into the left scrotum is the oldest reported patient with this complication. This type of migration tends to occur in younger children because of the higher incidence of a patent processus vaginalis and smaller volume of the peritoneal cavity in pediatric patients.

\section{References}

1) Bristow DL, Buntain WL, James HL: Ventriculoperitoneal (VP) shunt migration causing an acute scrotum: a case report of Doppler evaluation. J Pediatr Surg 13: 538-539, 1978

2) Cooper PR, Levey S, Rubin RC, Jacobs GB, Wille R: Distal shunt herniation simulating testicular torsion. Surg Neurol 6: 269-270, 1976

3) Crofford MJ, Balsam D: Scrotal migration of ventriculoperitoneal shunts. AJR Am J Roentgenol 141: 369-371, 1983

4) de Aquino HB, Carelli EF, Borges Neto AG, Pereira CU: Nonfunctional abdominal complications of the distal catheter on the treatment of hydrocephalus: an inflammatory hypothesis? Experience with six cases. Childs Nerv Syst 22: 1225-1230, 2006

5) Fuwa I, Matsukado Y, Itoyama Y, Yokota A: Migration of a dissected peritoneal shunt catheter into the scrotum. Brain Dev 6: 336-338, 1984

6) Grosfeld JL, Cooney DR: Inguinal hernia after ventriculoperitoneal shunt for hydrocephalus. J Pediatr Surg 9: 311-315, 1974

7) Karaosmanoglu D, Metin Y, Akata D, Haliloglu M: An unusual cause of hydrocele: malpositioned ventriculoperitoneal shunt in the scrotum. J Ultrasound Med 27: 159-160, 2008

8) Kobayashi H, Hayashi M, Kawano Y, Handa Y, Tsuji T, Ishii $\mathrm{H}$ : Migration of abdominal catheter of ventriculoperitoneal shunt into the scrotum. Zentralbl Neurochir 48: 232-234, 1987

9) Kwok CK, Yue CP, Wen HL: Bilateral scrotal migration of abdominal catheters: a rare complication of ventriculoperitoneal shunt. Surg Neurol 31: 330-331, 1989

10) Oktem IS, Akdemir H, Koc K, Menku A, Tucer B, Selcuklu 
A, Turan C: Migration of abdominal catheter of ventriculoperitoneal shunt into the scrotum. Acta Neurochir (Wien) 140: 167-170, 1998

11) Ozveren MF, Kazez A, Cetin H, Ziyal IM: Migration of the abdominal catheter of a ventriculoperitoneal shunt into the scrotum—case report. Neurol Med Chir (Tokyo) 39: 313-315, 1999

12) Rahman N, Lakhoo K: Patent processus vaginalis: a window to the abdomen. Afr J Paediatr Surg 6: 116-117, 2009

13) Ram Z, Findler G, Guttman I, Cherniak R, Knoller N, Shacked I: Ventriculoperitoneal shunt malfunction due to migration of the abdominal catheter into the scrotum. J Pediatr Surg 22: 1045-1046, 1987

14) Ramani PS: Extrusion of abdominal catheter of ventriculoperitoneal shunt into the scrotum. Case report. J Neurosurg 40: 772-773, 1974

15) Rowe MI, Copelson LW, Clatworthy HW: The patent processus vaginalis and the inguinal hernia. J Pediatr Surg 4: 102-107, 1969

16) Schmitt CP, Dotschmann R, Daschner M, Zimmering M, Greiner C, Boswald M, Klaus G, Schaefer F: Residual peritoneal volume and body size in children on peritoneal dialysis. [Members of the Mid European Pediatric Peritoneal Dialysis Study Group (MEPPS)]. Adv Perit Dial 15: 287-290, 1999

17) Villarejo FJ, Blazquez MG: Malfunctioning ven- triculoperitoneal shunt due to extrusion of the abdominal catheter into the scrotum. J Neurosurg Sci 24: 187-189, 1980

18) Walsh AR, Kombogiorgas D: Coiled ventricular-peritoneal shunt within the scrotum. Pediatr Neurosurg 40: 257-258, 2004

19) Ward JF, Moquin RR, Maurer ST: Expanding the differential diagnosis of the acute scrotum: ventriculoperitoneal shunt herniation. Urology 58: 281, 2001

20) Wong CW: Scrotal migration of a ventriculo-peritoneal shunt: report of a case. J Formos Med Assoc 93: 640-641, 1994

21) Wu Y, Green NL, Wrensch MR, Zhao S, Gupta N: Ventriculoperitoneal shunt complications in California: 1990 to 2000. Neurosurgery 61: 557-563, 2007

22) Yakabe S, Yamanouchi T: [Present state of inguinal hernia in children, especially contralateral appearance: The analysis of 5,686 cases survey with the 35th Kyushu Pediatric Surgical Congress questionnaire]. Nippon Shoni Geka Gakkai Zasshi 43: 32-36, 2007 (Japanese)

Address reprint requests to: Daisuke Kita, M.D., Department of Neurosurgery, Kanazawa University Hospital, Kanazawa University, 13-1 Takara-machi, Kanazawa 920-8641, Japan. e-mail:kitad@ns.m.kanazawa-u.ac.jp 